\title{
Microvillus Inclusion Disease Associated with Necrotizing Enterocolitis in a Premature Infant
}

\author{
Ersin Sayar ${ }^{1}$ Salih Kalay ${ }^{2}$ Aygen Yilmaz ${ }^{1}$ Osman Oztekin ${ }^{2} \quad$ Ali Islek $^{1} \quad$ Gulsum Ozlem Elpek $^{3}$ \\ Zuhal Kalay ${ }^{4}$ Gonul Tezel ${ }^{2}$ Reha Artan ${ }^{1}$
}

${ }^{1}$ Department of Pediatric Gastroenterology, Faculty of Medicine, Akdeniz University, Antalya, Turkey

2 Department of Neonatology, Faculty of Medicine, Akdeniz University, Antalya, Turkey

${ }^{3}$ Department of Pathology, Faculty of Medicine, Akdeniz University, Antalya, Turkey

${ }^{4}$ Department of Pediatrics, Faculty of Medicine, Akdeniz University, Antalya, Turkey

\begin{abstract}
Address for correspondence Dr. Salih Kalay, Department of Neonatology, Faculty of Medicine, Akdeniz University, Dumlupinar Bulvari, 07059, Kampus, Antalya, Turkey (e-mail: salihkalay@hotmail.com).
\end{abstract}

Am J Perinatol Rep 2014;4:e61-e64.

\author{
Abstract \\ Keywords \\ - microvillus inclusion \\ disease \\ - intractable diarrhea \\ - necrotizing \\ enterocolitis \\ - premature
}

Microvillus inclusion disease is one of the congenital diarrheal disorders characterized by the appearance of inclusion bodies on the intestinal epithelium. To date there are a few cases and also a few other associated finding reports related to this life-threatening disease in literature. In this report, we present a premature infant with microvillus inclusion disease that was associated with necrotizing enterocolitis. Thus, we should be aware of the appearance of necrotizing enterocolitis in patients with microvillus inclusion disease, especially when contributing factors are present.
Microvillus inclusion disease (MVID) is a protracted or intractable diarrhea syndrome, which is characterized by an early onset secretory diarrhea. The diagnosis can be established with light and electron microscopic findings of small bowel biopsies. ${ }^{1,2}$ The outcome is poor due to complications of total parenteral nutrition. The only definitive treatment option is intestinal transplantation. ${ }^{3}$ MVID is so rare that there are a few cases and also only a few other associate finding reports in English literature to date. Therefore, we present a report of a premature infant diagnosed as MVID associated with necrotizing enterocolitis (NEC).

\section{Case Presentation}

A 30-day-old, premature (34 weeks of gestation) female infant was transferred to our hospital with diarrhea and $29 \%$ of weight loss from birth. Her mother had been observed regularly by an obstetrician and polyhydramnios was noticed. The patient was delivered via a normal vaginal delivery, with an Apgar score of 8, 9 and a birth weight of $1,975 \mathrm{~g}$. At the 12th postnatal day she had been hospitalized in another center due to diarrhea that started on the 7th day, following dehydration and metabolic acidosis. Despite discontinuation of enteral nutrition, cholestyramine and fructose supplemented, carbohydrate-free formula usage, diarrhea became intractable (stool volume $>400 \mathrm{~mL} / \mathrm{kg} / \mathrm{d}$ ) and she was transferred to our hospital.

There was no family history of gastrointestinal disorders or immunodeficiency. Parents were second degree consanguineous. The patient had three healthy elder siblings. On physical examination, the patient did not have any dysmorphic feature. She was moderately dehydrated and malnourished. She had tachycardia and tachypnea. Her abdomen was distended and soft with normal bowel sounds and without masses. Other system examinations were normal.

Laboratory data revealed moderate metabolic acidosis. Stool osmotic gap was $(46 \mathrm{mOsm} / \mathrm{kg})$ indicating the secretory nature of diarrhea without selective chloride or sodium losses received

October 2, 2013 accepted after revision

December 24, 2013

published online

May 12, 2014
DOI http://dx.doi.org/

10.1055/s-0034-1370353. ISSN 2157-6998.
Copyright $\odot 2014$ by Thieme Medical Publishers, Inc., 333 Seventh Avenue, New York, NY 10001, USA. Tel: +1(212) 584-4662.
License terms

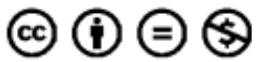




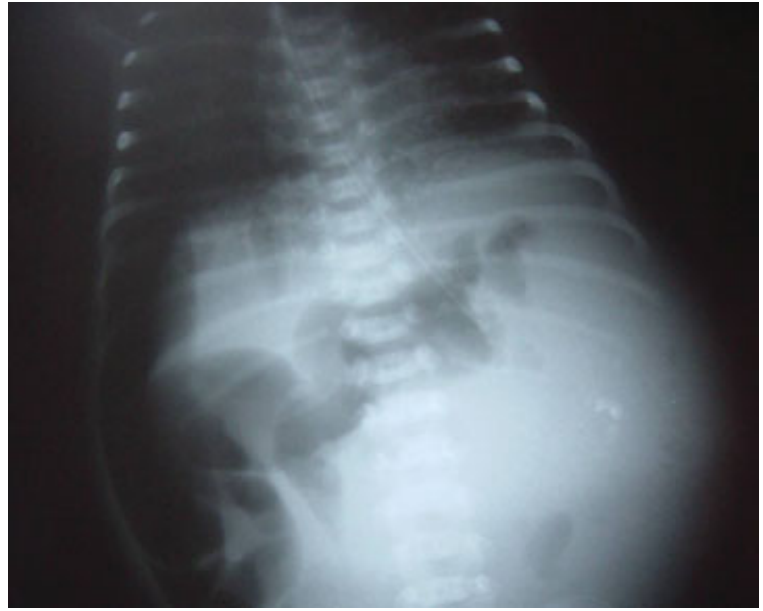

Fig. 1 Abdominal radiograph on lateral decubitus position reveals pneumoperitoneum with dilated bowel loops.

(stool: sodium, $77 \mathrm{mmol} / \mathrm{L}$; potassium, $45 \mathrm{mmol} / \mathrm{L}$; and chloride, $48 \mathrm{mmol} / \mathrm{L}$ ). The stool $\mathrm{pH}$ was always $>6$ and reducing substances were negative. Stool evaluations for infectious workup were all negative, including stool culture, parasite study, rotavirus, and adenovirus antigens, cryptosporidium and Clostridium difficile toxin, and cytomegalovirus DNA. She had a normal screen for inborn errors of metabolism including serum amino acids and urine organic acids. She required fluid intake $(400 \mathrm{~mL} / \mathrm{kg} / \mathrm{d})$ containing sodium (30 mmol $/ \mathrm{kg} / \mathrm{d}$ ) to maintain hydration and electrolyte balance.

Septic workup was performed and antibiotic therapy was started due to possibility of NEC because of appearance of fixed intestinal loops on repeated abdominal roentgenograms. The stool volume reduced (from 400 to $100 \mathrm{~mL} / \mathrm{kg} / \mathrm{d}$ ), abdominal distension regressed, and minimal enteral feeding begun following 10 days of bowel rest. At fourth day of enteral feeding gastrointestinal symptoms (nausea, tender and distended abdomen, bloody stool) occurred suddenly. Arterial blood gases exhibited metabolic acidosis. In several hours the symptoms worsened dramatically and abdominal skin discoloration was shown. Due to demonstration of pneumoperitoneum on abdominal radiograph (-Fig. 1) laparotomy was performed, which revealed necrotic intestinal tissue limited to 5 to $6 \mathrm{~cm}$ in jejunum. Total of $10 \mathrm{~cm}$ small bowel was resected including additional safety tissue from both sides. Histopathological examination, which gets prepared from middle of the material, confirmed wall necrosis and pneumatosis, while no findings in favor of NEC was shown from lateral sides. In a short time after operation she required mechanical ventilation support and died from probable sepsis.

Light microscopy on preserved small bowel biopsies with periodic acid-Schiff (PAS) staining showed lack of the normal brush border and PAS-positive diastase resistant densities at the apex of the enterocytes (-Fig. 2). Electron microscopy studies revealed that most of microvilli were absent and the rest were stubby at the apical surface of an enterocyte.


Fig. 2 (a) The periodic acid-Schiff (PAS) stain with diastase demonstrates the intestinal brush border is not well outlined as in normal mucosa. In contrast, PAS-positive diastase resistant densities at the apex of the enterocytes are noted (arrows). (b) Similar findings are observed using immunohistochemical staining for carcinoembryonic antigen (CEA). CEA-positive densities are present at the apex of the cytoplasm and brush border remains negative (arrows). Magnification (a) D-PAS, $\times 400$; (b) CEA immunostaining, counterstained with Harris hematoxylin, $\times 200$.

Vesicular structures located toward the apex were present (-Fig. 3). Thus, MVID diagnosis was made. We could not provide genetic study for the MYO5B gene mutation due to rejection of the family for further research.

\section{Discussion}

The term "congenital diarrheal disorders" is used for patients usually present with life-threatening diarrhea due to dehydration and metabolic acidosis, in the first days or weeks of life. One of them MVID, which appears at first days (early onset form) or first months (late onset form) of life, is characterized by life-threatening secretory diarrhea. ${ }^{1,2}$

MVID is an autosomal recessive disease caused by MYO5B gene mutations that disrupt epithelial cell polarity. MYO5B gene encodes myosin $\mathrm{Vb}$ that regulates membrane trafficking along the recycling pathway in polarized epithelial cells. ${ }^{4,5}$ Prenatal diagnosis could be possible and first prenatal 


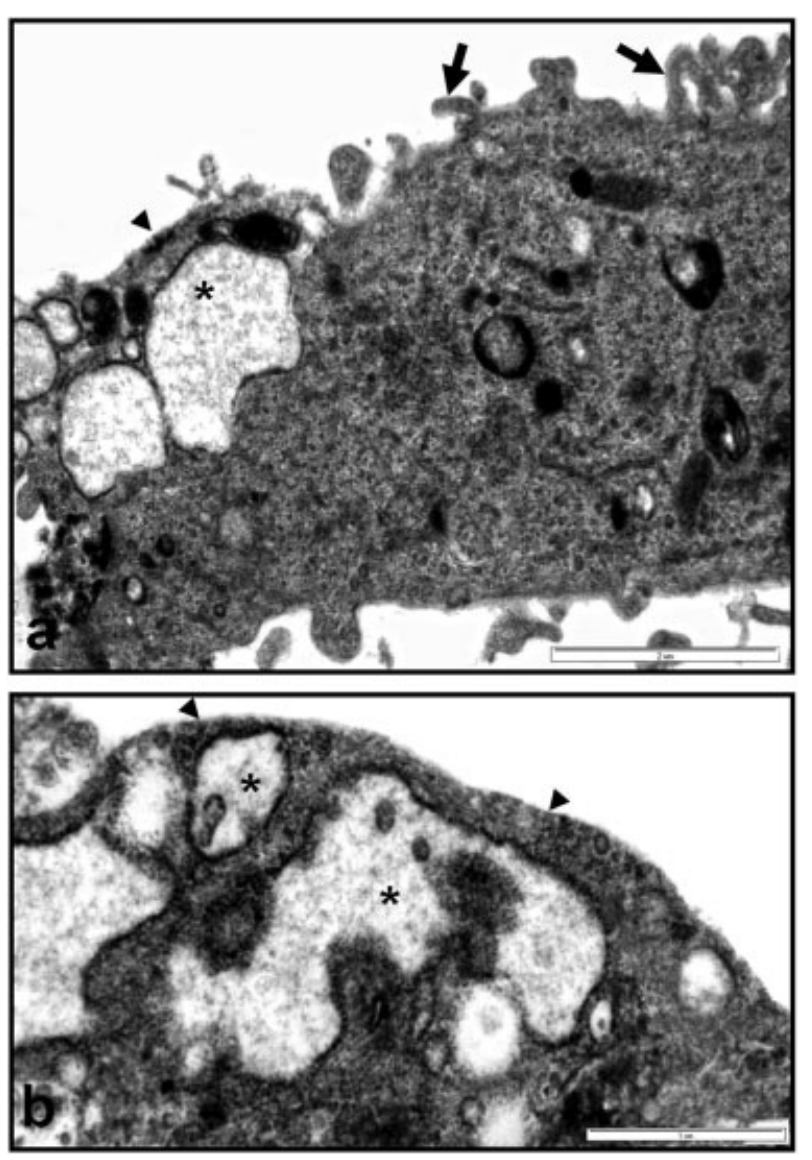

Fig. 3 Ultrastructural findings. (a) At the apical surface of an enterocyte most of microvilli are absent (arrow head) and the remaining are stubby (arrows). Vesicular structures located toward the apex are present (asterisk). (b) In higher magnification any microvilli is not observed at the apex (arrow) of another enterocyte. Dilated spaces (asterisks) containing vesicular structure and a few round forms resembling microvilli are present. Magnification (a) $\times 7,750$ and (b) $\times 16,700$.

diagnosis has been recently published. ${ }^{6}$ Intestinal histology shows villous atrophy without marked crypt hyperplasia and abnormal PAS-positive inclusion material in the apical cytoplasm. In electron microscopy atrophic or completely absent microvilli and secretory granules appear in the same distribution as the abnormal PAS-positive accumulation. ${ }^{1}$ Light and electron microscopic findings in our patient's jejunum specimens are consistent with stated above. But distinct histological diagnosis made from surgically resected small bowel specimens.

To our knowledge there are not any data reported about MVID and NEC association or their relationship. Three key contributing factors have been identified about pathophysiology of NEC; early enteral feeding, bacterial colonization, and prematurity. ${ }^{7}$ Colonization of the newborn's intestine is affected by a variety of factors such as delivery method, gestational age, breast- or formula-feeding, and using of broad-spectrum antibiotics. ${ }^{8}$ Prematurity, formula feeding, and broad-spectrum antibiotics usage might lead to bacterial colonization related to NEC, in our patient. It was expressed that mainly prolonged catheter-related sepsis is the major cause of death in MVID. Similarly, the reason of death in our patient could be probable sepsis secondary to NEC; despite we did not prove it with cultures. ${ }^{1}$

Few other disease associations with MVID are reported in literature. One patient diagnosed as dihydropyrimidinase deficient. ${ }^{9}$ One had severe mental retardation of unspecified etiology. ${ }^{10}$ It was debated whether hypophosphatemic rickets and renal insufficiency were results of complications from stool losses in two patients. ${ }^{10,11}$ Another one was associated with coarctation of the aorta and bicuspid aortic valve. ${ }^{12}$

There is no report of MVID and NEC association and also no data to determine a link between the two conditions. Although, the association may be coincidental, we should be aware of appearing NEC in patients with MVID especially when contributing factors present.

\section{References}

1 Goulet OJ, Phillips AD. Congenital enteropathies. In: Kleinman RE, Goulet OJ, Mieli-Vergani G, Sanderson IR, Sherman PM, Shneider BL, eds. Walker's pediatric gastrointestinal disease. Shelton, CT: People's medical publishing house; 2008:309-318

2 Berni Canani R, Terrin G, Cardillo G, Tomaiuolo R, Castaldo G. Congenital diarrheal disorders: improved understanding of gene defects is leading to advances in intestinal physiology and clinical management. J Pediatr Gastroenterol Nutr 2010;50(4):360-366

3 Halac U, Lacaille F, Joly F, et al. Microvillous inclusion disease: how to improve the prognosis of a severe congenital enterocyte disorder. J Pediatr Gastroenterol Nutr 2011;52(4):460-465

4 Müller T, Hess MW, Schiefermeier N, et al. MYO5B mutations cause microvillus inclusion disease and disrupt epithelial cell polarity. Nat Genet 2008;40(10):1163-1165

5 Erickson RP, Larson-Thomé K, Valenzuela RK, Whitaker SE, Shub MD. Navajo microvillous inclusion disease is due to a mutation in MYO5B. Am J Med Genet A 2008;146A(24):3117-3119

6 Chen CP, Su YN, Chern SR, Wu PC, Wang W. Prenatal diagnosis of microvillus inclusion disease. Taiwan J Obstet Gynecol 2011;50(3): 399-400

7 Hsueh W, Caplan MS, Qu XW, Tan XD, De Plaen IG, Gonzalez-Crussi F. Neonatal necrotizing enterocolitis: clinical considerations and pathogenetic concepts. Pediatr Dev Pathol 2003;6(1):6-23

8 Claud EC, Walker WA. Bacterial colonization, probiotics, and necrotizing enterocolitis. J Clin Gastroenterol 2008;42(Suppl 2): S46-S52

9 Assmann B, Hoffmann GF, Wagner L, et al. Dihydropyrimidinase deficiency and congenital microvillous atrophy: coincidence or genetic relation? J Inherit Metab Dis 1997;20(5):681-688

10 Ruemmele FM, Jan D, Lacaille F, et al. New perspectives for children with microvillous inclusion disease: early small bowel transplantation. Transplantation 2004;77(7):1024-1028

11 Kagitani K, Yamamoto T, Miki K, et al. Hypophosphatemic rickets accompanying congenital microvillous atrophy. J Bone Miner Res 1998;13(12):1946-1952

12 Gathungu GN, Pashankar DS, Sarita-Reyes CD, et al. Microvillus inclusion disease associated with coarctation of the aorta and bicuspid aortic valve. J Clin Gastroenterol 2008;42(4):400-403 